\title{
IMPACT OF CORROSION EFFECT ON THE QUALITY AND SAFETY OF REFRACTORY MATERIALS
}

doi: $\quad 10.2478 /$ czoto-2019-0097

Date of submission of the article to the Editor: 25/11/2018

Date of acceptance of the article by the Editor: 29/12/2018

Marek Šolc ${ }^{1}$ - orcid id: 0000-0001-7906-6405

Martin Kotus ${ }^{2}$ - orcid id: 0000-0002-0630-8132

Eva Grambalová ${ }^{-}$orcid id: 0000-0003-3479-880X

Juraj Kliment ${ }^{1}$ - orcid id: 0000-0002-1160-987X

Pavol Palfy ${ }^{1}$ - orcid id: 0000-0001-8332-2192

${ }^{1}$ Technical University of Košice, Slovak Republic

${ }^{2}$ Slovak University of Agriculture, Slovak Republic martin.kotus@uniag.sk

Abstract: The quality of refractory materials plays an important role especially in high temperature processes. In case of violation of qualitative properties of refractory materials, the safety of the use of the technological equipment in which these materials are used is compromised. The requirements on the quality of refractories and their properties are now high, as their operating life should be as long as possible. The aim of the article is to point out the quality of refractory material in contact with corrosive media, to analyze the technological factors that affect the quality and safety of technological equipment. An analysis of the refractory material, as well as the analysis of the melt was performed. Subsequently, an experiment was realized, which was evaluated by macroscopic analysis and chemical analysis. After the experiments, we found that the melt had penetrated the masonry and consequently created corrosion layers in the masonry. These layers have affected the life of the material and reduced the safety of the technological equipment in which they were used.

Keywords: refractory material, process, corrosion, requirements

\section{INTRODUCTION}

Quality and safety from the management perspective must be seen not only in terms of product quality and safety, but also in terms of quality of service, quality of new production processes, from production preparation to servicing, quality of productiontechnical base, quality of the environment and quality of management. An important aspect of a thriving organization is to gain the trust of the customer. (Šolc et al., 2014) Quality is the sum of the measurable and non-measurable properties of the service or product, features, and characteristics that determine the extent of their ability to perform the functions for which they are intended. Quality and safety is currently considered to be an important asset in which it is possible to see a competitive 
advantage and it is actually the satisfaction of the owners of the company, employees and customers as well (Nenadál et al., 2008). From the point of view of the entrepreneur, there is ever increasing emphasis is on it and today it is a crucial element of the economic development of the company and its success (Leščišin, 2006). Organizations must be able to adapt to market and market and customer requirements because the seller's market is transformed into the buyer's market (Prístavka and Bujna, 2014). In a competitive environment, quality and safety are in the focus of attention (Pačaiová et al., 2015).

For each business and industry, quality and safety is an essential tool for maintaining and enhancing competitiveness and is not only understood as a factor of image, but becomes a matter of survival and must be taken into account in all management decisions. Quality is not just the quality of the product, but also the time of entry to the market, the cost and flexibility of the company's ability to respond to customer requirements.

The word quality is mostly used as an expression of evaluation and, depending on the context in which we use it, we give it different content. The function of inspection is the timely detection of deviations in the controlled process between planning and implementation, which may have a negative or positive impact on the production process. The product quality depends on quality of manufacturing process. (Záhorská et al., 2016; Brozova et at., 2013; Jonšta et al., 2016) What is good for someone, the same may not be good for another. This is what makes quality subjective. Essential features of quality include: usability; functionality and performance; equipment; reliability; compliance with the requirements; durability; the level of operation or service; ecological soundness; safety; design (shape and color).

Refractory materials are characterized as ceramic materials, exposed during their use to high temperatures, and often to other extreme chemical and physical exposures that limit their operation life (Staroň and Tomšŭ, 1992). The intensive use of refractories in steelmaking plants is due to the properties these compounds exhibit such as high starting melting point, high structural strength at high temperatures and in highly corrosive environments, and an intensive stability in temperature variations (Borges and Lenz e Silva, 2017). What is common for refractory materials in terms of not only various applications but also their material and structural nature is described by a set of properties of refractory materials, which is as follows (Vert and Smith, 2016):

- the density criteria,

- mechanical properties,

- thermal properties,

- thermomechanical properties

- resistance to sudden temperature changes,

- chemical and mineralogical properties,

- thermochemical and thermophysical properties.

All refractory samples suffered from a high chemical attack in combination with high thermal load (Gregurek et al., 2016). When assessing the quality requirements for refractories, it is important to know the limits of achievable properties (Dulebová and Hovanec, 2015). In order to understand the nature of the individual properties, it is necessary to consider to what extent the resulting property is influenced by the human activity and to what extent by the natural properties of the material according to the following figure 1. 


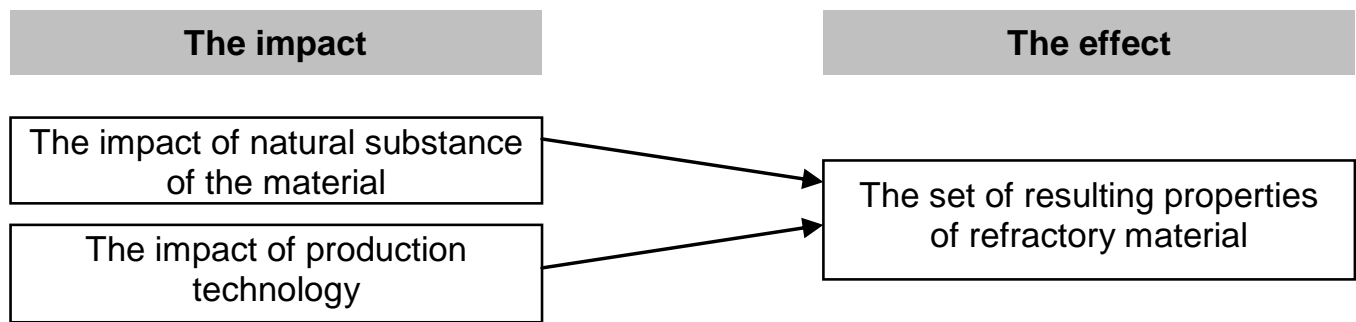

Fig. 1. The basics for understanding the properties of materials (Hanykýř and Kutzendörfer, 2002)

Selected characteristics of refractory materials are evaluated using known statistical methods and state-of-the-art statistical programs. Large amount of data can be statistically processed in a relatively short time. The obtained graphical outputs are clear and comprehensible. The language of statistics has become an essential element of communication between suppliers and customers in the area of products and services quality. For the evaluation of the quality of the refractory bricks are used the methods for testing the refractory materials, which are defined in STN, and EN ISO respectively. These standards include the following methods:

- determination of the chemical composition,

- determination of the phase composition,

- testing the physical and mechanical properties of refractory products.

\section{MATERIALS AND METHODS}

Two basic raw materials were used for the experiment: refractory material and corrosive medium (coating salt). The refractory alumino-silicate material with the designation $A$. The primary composition of the alumino-silicate refractory material obtained by chemical analysis is shown in table 1 .

Table 1

Results of the chemical analysis of the aluminum-silicate refractory sample

\begin{tabular}{|c|c|c|c|c|c|c|c|c|}
\hline & \multicolumn{8}{|c|}{ Chemical analysis [wt. \%] } \\
\hline Sample & $\mathrm{Al}$ & $\mathrm{Ca}$ & $\mathrm{Si}$ & $\mathrm{Fe}$ & $\mathrm{Ti}$ & $\mathrm{Na}$ & $\mathrm{Mg}$ & $\mathrm{K}$ \\
\hline $\mathrm{A}$ & 38.73 & 4.3 & 1.75 & 1.14 & 0.95 & 0.22 & 0.25 & 0.15 \\
\hline
\end{tabular}

The phase composition of the alumino-silicate refractory material reported by the manufacturer and the composition obtained is given in table 2.

Table 2

The phase composition of the alumino-silicate refractory sample

\begin{tabular}{|c|c|c|c|c|c|c|c|c|}
\hline & \multicolumn{7}{|c|}{ Chemical analysis [wt. \%] } \\
\hline Sample & $\mathrm{Al}_{2} \mathrm{Si}_{3}$ & $\mathrm{SiO}_{2}$ & $\mathrm{CaO}$ & $\mathrm{Fe}_{2} \mathrm{O}_{3}$ & $\mathrm{TiO}_{2}$ & $\mathrm{Na}_{2} \mathrm{O}$ & $\mathrm{MgO}$ & $\mathrm{K}_{2} \mathrm{O}$ \\
\hline A producer & 78 & 12 & 0.7 & 1.1 & - & - & - & - \\
\hline A analysis & 73.2 & 3.75 & 6.01 & 1.63 & 1.6 & 0.3 & 0.35 & 0.18 \\
\hline
\end{tabular}

By comparison of phase analyzes reported by the manufacturer and obtained by phase chemical analysis, it is clear that the weight percent reported by the manufacturer is not accurate. 
Phase diffraction analysis (XDR) of alumino-silicate sample $A$ is shown in figure 2 . It was measured on a Rigak MiniFlex 600 diffractometer (radiatiation CuKa Ni filter, Bragg-Brentano goniometer, Theta-2Theta arrangement, voltage $40 \mathrm{kV}$, current 15 $m A)$.

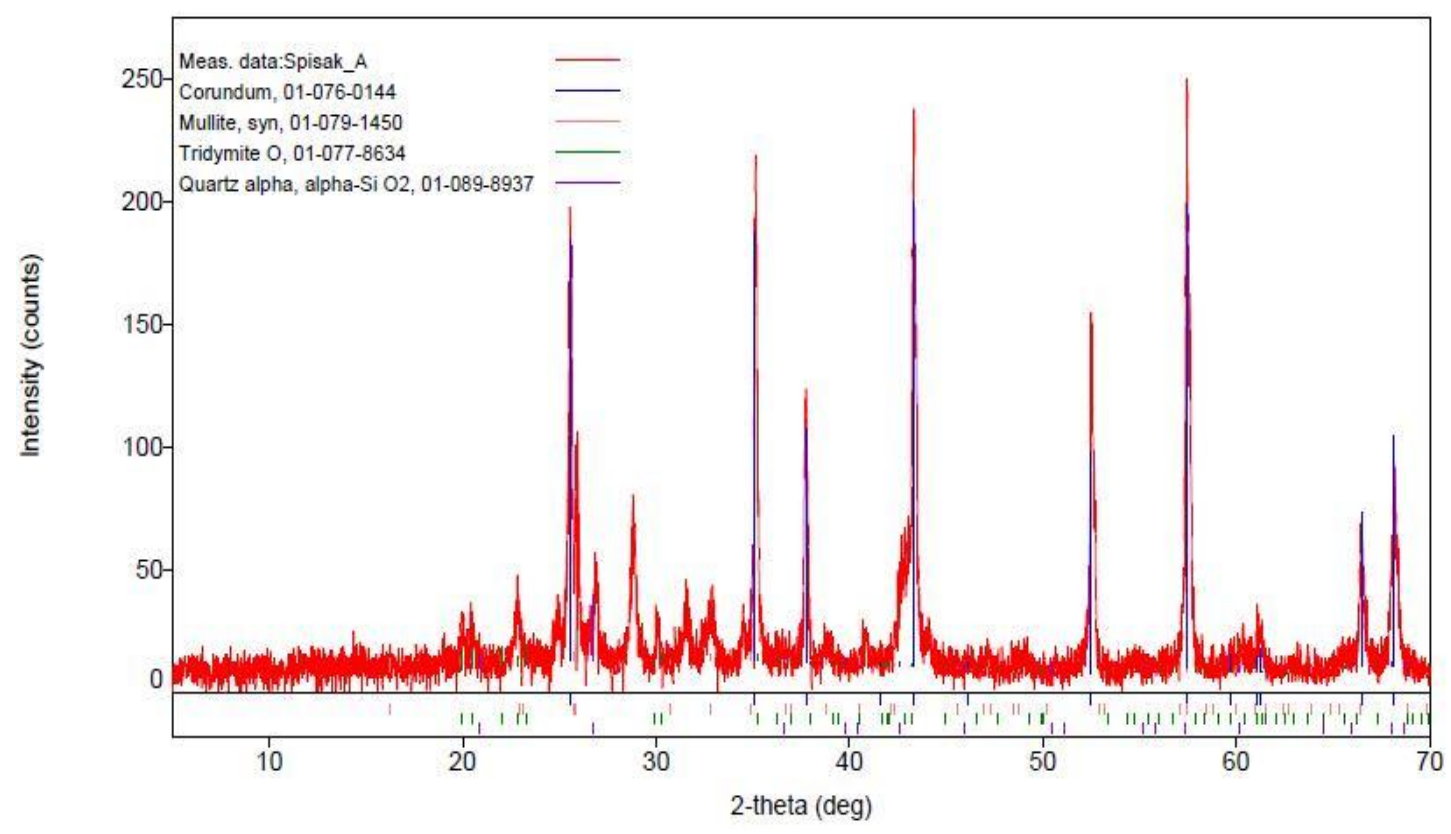

Fig. 2. XDR Phase analysis of refractory material $A$

The various properties of the used refractory material $A$, provided by the manufacturer, are shown in table 3.

Table 3

Properties of the sample A

\begin{tabular}{|c|c|c|c|c|c|}
\hline Property & Bond & $\begin{array}{c}\text { Raw } \\
\text { material }\end{array}$ & $\begin{array}{c}\text { Specific weight } \\
{\left[\mathrm{g}_{\mathrm{cm}}{ }^{-3}\right]}\end{array}$ & $\begin{array}{c}\text { Thermal conductivity } \\
{\left[\mathrm{W} \cdot \mathrm{m}^{-1} \cdot \mathrm{K}^{-1}\right]}\end{array}$ & $\begin{array}{c}\text { Cold strength } \\
{[\mathrm{MPa}]}\end{array}$ \\
\hline A & Hydraulic & Bauxit & 2.9 & 2.3 & 100 \\
\hline
\end{tabular}

The corrosive medium is a solid or fluid (at room temperature), which is charged into the drilled holes, reacts with a refractory material, and the products of the reaction are substances (products) no longer belonging to the group of refractory materials, do not form a ceramic bond with the original refractory material, by which actually disturb the structure of the original material, that loses its refractory properties while being degraded and worn. The composition of the corrosive medium is given in table 4 and table 5 .

Table 4

Elemental chemical analysis of the coating salt

\begin{tabular}{|c|c|c|c|c|c|}
\hline & \multicolumn{5}{|c|}{ Elemental chemical analysis [wt. \%] } \\
\cline { 2 - 6 } & $\mathrm{Mg}$ & $\mathrm{K}$ & $\mathrm{Ca}$ & $\mathrm{Na}$ & $\mathrm{Cl}^{-}$ \\
\hline Coating salt & 21.17 & 16.77 & 0.24 & 0.105 & 40.97 \\
\hline
\end{tabular}


Table 5

Phase chemical analysis of the coating salt

\begin{tabular}{|c|c|c|}
\hline & \multicolumn{2}{|c|}{ Phase chemical analysis [wt. \%] } \\
\hline & $\mathrm{MgCl}_{2}$ & $\mathrm{KCl}$ \\
\hline Coating salt & 54.61 & 31.97 \\
\hline
\end{tabular}

Chemical analysis of elements has shown that the coating salt contains mainly alkali metals ( $\mathrm{K}$ and $\mathrm{Na}$ ), alkaline earth metals $(\mathrm{Mg}$ and $\mathrm{Ca}$ ) and chloride anions (Cl-). It confirmed the presence of chloride anions, potassium and magnesium in the form of potassium chloride $(\mathrm{KCl})$ and magnesium chloride $\left(\mathrm{MgCl}_{2}\right)$. To test the interactions of the refractory materials of $\mathrm{Al}_{2} \mathrm{O}_{3}-\mathrm{SiO}_{2}$ system and the melts of the $\mathrm{KCl}^{-} \mathrm{MgCl}_{2}$ system, a static crucible test was chosen. The refractories were cast into a $100 \times 100 \times 100 \mathrm{~mm}$ mold before solidification. The materials were solidified and dried in this form, then a hole $20 \mathrm{~mm}$ in diameter and $30 \mathrm{~mm}$ deep was drilled into them. The hole was subsequently filled with corrosion medium. The amount of used coating salt was about $17 \mathrm{~g}$; this weight does not imply a precisely weighed weight, it is the weight loss of the corrosion medium after the holes are filled. The static corrosion tests were performed in an electric resistive furnace under air atmosphere $\left(\mathrm{pO}_{2}=0.212 \mathrm{MPa}\right)$ where the samples were heated to the appropriate corrosion test temperature. After holding at the appropriate sample temperature, the samples in the furnace were freely cooled. After cooling, the samples were retrieved from the furnace and transversely dry cut with a diamond disk saw and documented. The corrosion test was performed visually by the naked eye and the infiltration or penetration depths and changes in the refractory material were compared. The temperature, to which the crucibles were heated was $850{ }^{\circ} \mathrm{C}$. This temperature was chosen based on the $\mathrm{KCl}-\mathrm{MgCl}_{2}$ system so that the melt was evenly homogeneous during the experiment. The holding time after reaching the correct temperature was 2 hours.

\section{RESULTS AND DISCUSSION}

\subsection{Macroscopic analysis}

The results of the macroscopic analysis are shown in figures 3 and 4 . The measured penetration values are shown in table 6 .
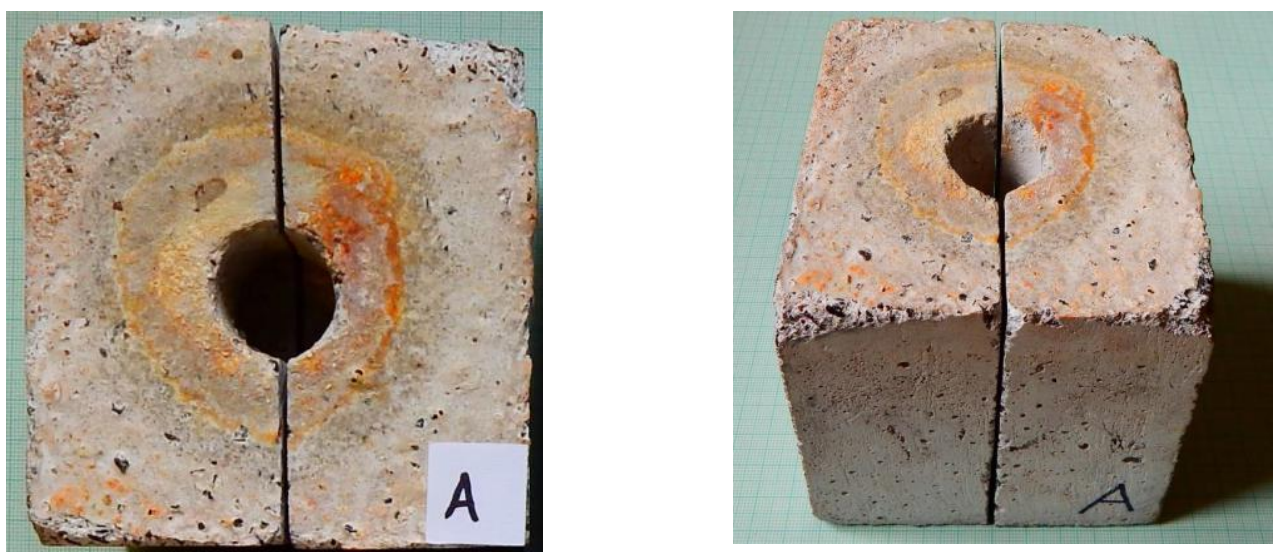

Fig. 3. Sample after cutting - top and side view

From the top view, it is possible to see that a large surface corrosion has occurred in the sample. However, after the sample was cut, it has been found that there is much less of impregnated zones and their observability is much harder. From that follows that surface corrosion is not real, it is either a thin film of corrosion, or corrosive 
medium has boiled out during the thermal decomposition and stained the surface of the samples.

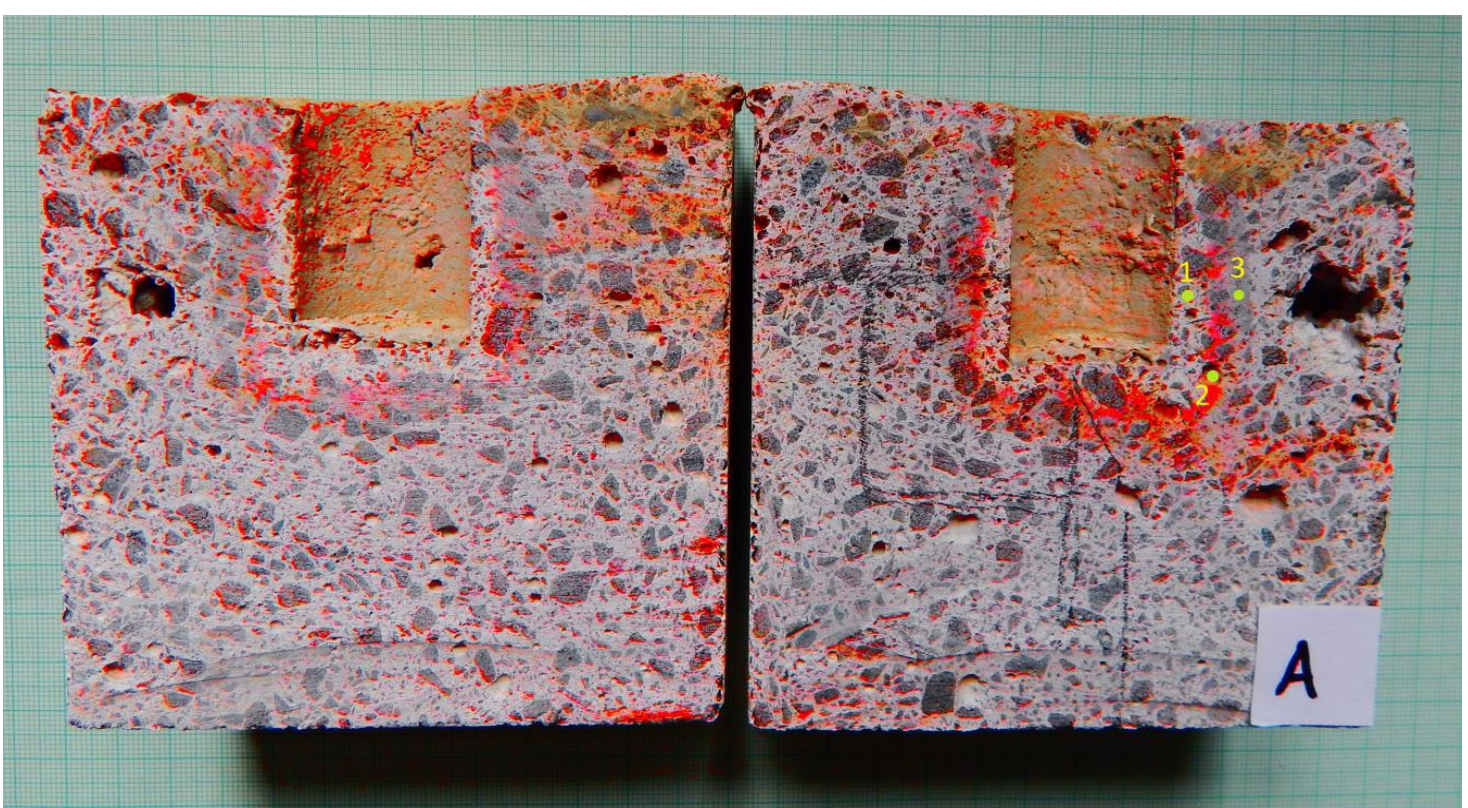

Fig. 4. Cut sample after graphic adjustment (measuring zones are indicated in the picture by numbers 1,2 and 3 )

Table 6

The depth of infiltration of the corrosion medium on the sample A

\begin{tabular}{|c|c|c|c|c|}
\hline Sample label & Measurement & Measurement & \multicolumn{2}{|c|}{ Infiltration depth [mm] } \\
\hline \multirow{12}{*}{ A } & \multirow{4}{*}{ Zone 1} & \multirow[b]{2}{*}{ Side } & Interval & $1.61-4.33$ \\
\hline & & & Arithmetic mean & 2.97 \\
\hline & & \multirow{2}{*}{ Bottom } & Interval & $1.71-4.54$ \\
\hline & & & Arithmetic mean & 3.13 \\
\hline & \multirow{4}{*}{ Zone 2} & \multirow{2}{*}{ Side } & Interval & $2.22-7.56$ \\
\hline & & & Arithmetic mean & 4.89 \\
\hline & & \multirow{2}{*}{ Bottom } & Interval & $6.65-10.79$ \\
\hline & & & Arithmetic mean & 8.72 \\
\hline & \multirow{4}{*}{ Zone 3} & \multirow{2}{*}{ Side } & Interval & $6.55-10.28$ \\
\hline & & & Arithmetic mean & 8.42 \\
\hline & & \multirow{2}{*}{ Bottom } & Interval & $9.17-12.7$ \\
\hline & & & Arithmetic mean & 10.94 \\
\hline
\end{tabular}

Sample A had three corrosion zones, it can be regarded as highly corrosion-resistant with an average maximum infiltration of $10.94 \mathrm{~mm}$.

\subsection{Chemical analysis}

To confirm the course of coating salt impregnation in the samples, chemical analyzes were made from four different parts of the refractory material, namely:
A) the impregnated area - near the opening (approx. $2 \mathrm{~mm}$ )
B) impregnated area - distant from the opening (approx. $10 \mathrm{~mm}$ )
C) probably impregnated area (approx. $25 \mathrm{~mm}$ )
D) presumably non-impregnated area (approx. $60 \mathrm{~mm}$ )

The results of the chemical analysis are shown in table 7 and figure 5 . 
Table 7

Chemical elemental and phase analysis of sample A from the sampled areas

\begin{tabular}{|c|c|c|c|c|c|}
\hline Sampling area & \multicolumn{3}{|c|}{ Chemical elemental analysis [wt. \%] } & \multicolumn{2}{|c|}{ Chemical phase analysis [wt. \%] } \\
\hline $\begin{array}{l}\text { Distance from } \\
\text { the hole }\end{array}$ & $\mathrm{Mg}$ & $\mathbf{K}$ & $\mathrm{Cl}$ & $\mathrm{MgCl}_{2}$ & $\mathrm{KCl}$ \\
\hline 2 & 1.03 & 0.53 & 2.11 & 4.03 & 1.11 \\
\hline 10 & 0.2 & 0.22 & 1.9 & 0.78 & 0.46 \\
\hline 25 & 0.16 & 0.014 & 0.33 & 0.62 & 0.02 \\
\hline 60 & 0.15 & 0.014 & 0.33 & 0.58 & 0.02 \\
\hline
\end{tabular}

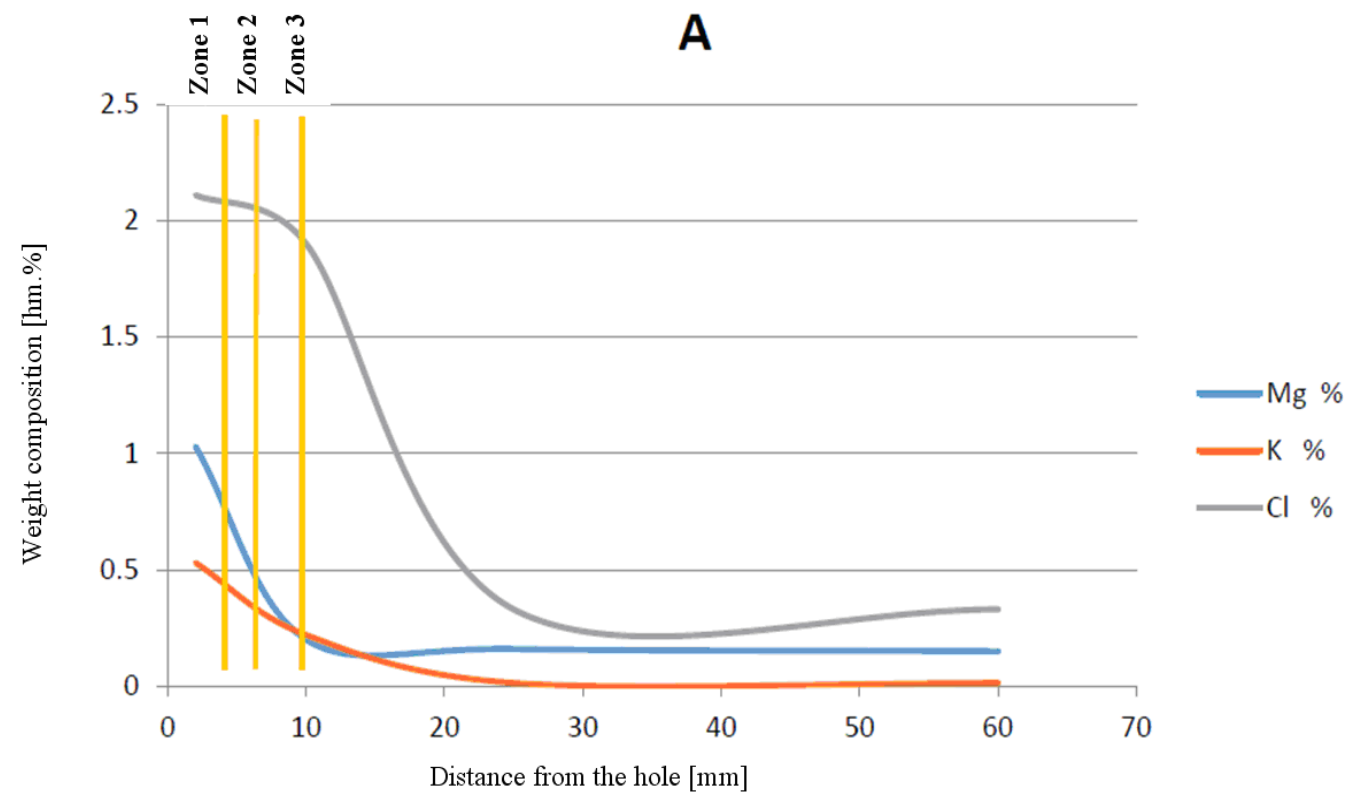

Fig. 5. Content of $\mathrm{K}, \mathrm{MgCl}$ in sample A with indicated corrosion zones

The figure 5 shows the results of a chemical analysis of sample $A$, focused on the main elements (ions) of the corrosive medium with indicated corrosion zones. As assumed, chlorine has the largest share, which means that mainly chlorides have been produced by corrosion. For sample A, shares of magnesium and potassium are very low. Their sum (mainly from the beginning) is lower than that of chlorine alone. By comparison with the macroscopic analysis (zones shown in figure 5), it is clear that all three layers are mainly chloride compounds. This is mainly due to the fact that the loss of chlorine is minimal while the visible corrosion zones are visible in the sample. When the third corrosive layer disappears, the chlorine content drops sharply.

\section{CONCLUSION}

From the results of the corrosion tests carried out we can state that the melt has penetrated the masonry, causing chemical reactions and creating various corrosion layers in the masonry; Sample A had a very resistant side walls of the opening; The content of $\mathrm{Mg}^{+2}, \mathrm{~K}^{+}$and $\mathrm{Cl}^{-}$in the masonry exponentially declined; the corrosive zones on the surface were probably caused by the boiling out of the corrosive medium. High alumina refractory materials with a lower $\mathrm{Al}_{2} \mathrm{O}_{3}$ content are more corrosion-resistant against the tested coating salt than materials with a higher content of $\mathrm{Al}_{2} \mathrm{O}_{3}$.

Perfect knowledge of the individual qualitative properties of refractories during their operation is very important. A fundamental understanding of refractory performance at high temperatures is the best approach to decreasing energy consumption, reducing 
downtime, and increasing the campaign life of blast furnaces (Zuo et al., 2017). If there were frequent repairs, maintenance and downtime, that could significantly increase costs and reduce market competitiveness. The main condition for assessing the suitability of the refractory material is therefore achieving the longest possible durability in the processes.

\section{ACKNOWLEDGEMENTS}

The paper is related to the research project KEGA 008TU Z-4/2016 "New Forms and Methods of Education in Area of Machinery Safety".

\section{REFERENCES}

Borgez, R.A.A., Lenz de silva, G.F.B., 2017. A statistical and post-mortem study of wear and performance of $\mathrm{MgO}-\mathrm{C}$ resin bonded refractories used on the slag line ladle of a basic oxygen steelmaking plant. Engineerig Failure Analysis, 78, 161168. DOI: 10.1016/j.engfailanal.2017.03.020

Brozova, S., Ingaldi, M., Sperlin, I., 2013. Economical aspects of high-temperature heating utilization for industrial waste treatment. METAL 2013: 22nd International Conference On Metallurgy And Materials, 1735-1739.

Dulebová, M., Hovanec, M., 2015. Assessment of porosity as one of the indicators of the quality of engineering products. Safety - Quality - Reliability 2015, Košice, TU Košice, 31-37.

Gregurez, D., Wenzl, C., Kreuzer, D., Spanring, A., Kirschen, M., Zeelie, D., Groenewald, J., 2016. Refractory Corrosion Mechanisms in a Novel High Carbon Ferromanganese Production Furnace. The journal of the Minerals, Metals \& Materials Society, 68(12), 3029-3039. DOI: 10.1007/s11837-016-2110-z

Hankýřr, V., Kutzendörfer, J., 2002. Ceramics technology. first ed. Vega, Hradec Králove, Czech Republic.

Jonšta P., Váňová P., Brožová S., Pustějovská P., Sojka J., Jonšta Z., Ingaldi M. Hydrogen embrittlement of welded joint made of supermartensitic stainless steel in environment containing sulfane. Archives of Metallurgy and Materials, 2016, vo. $61, \mathrm{Nr} 2 \mathrm{~A}$, s. $709-712$

Leščišin, M., 2006. Quality management. first ed. Ekonóm, Bratislava, Slovakia.

Nenadál, J., Noskievičová, D., Petříková, R., Plura, J., Tošenovský, J., 2008. Modern Quality Management. first ed. Management press, Brno, Czech Republic.

Pačaiová, H., Markulik, Š., Turisová, R., Nagyová, A., Namešanská, J., 2015. Quality of production. first ed. TU Košice, Košice, Slovakia.

Prístavka, M., Bujna, M., 2014. Monitoring the capability of production equipment in organization. Acta Technologica Agriculturae, 17(2), 39-43. DOI: https://doi.org/10.2478/ata-2014-0009

Šolc, M., Grambalová, E., Šofranko, M., 2014. The quality interaction of molten salts in the systems $\mathrm{SiO}_{2}-\mathrm{Al}_{2} \mathrm{O}_{3}$., Advanced Materials Research, 849, 20-25, DOI: 10.4028/www.scientific.net/AMR.849.20

Staroň, J., Tomašu, F., 1992. Refractory materials - production, properties, use. Media, Banská Bystrica, Slovakia.

Vert, T., Smith, D. J., 2016. Refractory Materials Selection for Steelmaking. first ed. Wiley, American Ceramics Society, United States of America.

Záhorská, R., Nozdrovický, L., Mikulášik, L', 2016. Implementation of statistical methods and swot analysis for evaluation of metal waste management in engineering company. Acta Technologica Agriculturae, 19(4), 89-95, DOI: https://doi.org/10.1515/ata-2016-0018

Zuo, H., Wang, C., Liu, Y., 2017. Dissolution behavior of a novel $\mathrm{Al}_{2} \mathrm{O}_{3}-\mathrm{SiC}-\mathrm{SiO}_{2}-\mathrm{C}$ composite refractory in blast furnace slag. Ceramics International, 43(9), 70807087. DOI: https://doi.org/10.1016/j.ceramint.2017.02.138 